\title{
Sahil Beldesi Selimpaşa'da Kentsel Yaşam Kalitesi ve Turizmin Canlanmasına Etki Edebilecek Mevcut Potansiyellerin Araştırılması ve Kullanımı için Çözüm Önerileri
}

\author{
Zeynep Kerem Öztürk ${ }^{\mathrm{a} 1, *}$, Mertcan Y1lmaz ${ }^{\mathrm{a} 2}$ \\ a İstanbul Sabahattin Zaim Üniversitesi, Mühendislik ve Doğa Bilimleri Fakültesi, Mimarlık Bölümü, İstanbul, Türkiye \\ b İstanbul Sabahattin Zaim Üniversitesi, Lisansüstü Eğitim Enstitüsü, Mimarlık Yüksek Lisans Programı, İstanbul, Türkiye
}

İstanbul Sabahattin Zaim Üniversitesi Fen Bilimleri Enstitüsü Dergisi (2021) 3 (2): 178-183

https://doi.org/10.47769/izufbed.927814

(iD) $O R C I D{ }^{1} 0000-0001-7691-9126 ;{ }^{2} 0000-0003-3395-8269$

\begin{tabular}{l}
\hline YAYIN BİLGİSI \\
\hline Yayın geçmişi: \\
Gönderilen tarih: 25 Nisan, 2021 \\
Kabul tarihi:14 Haziran 2021 \\
\\
Anahtar kelimeler: \\
Selimpaşa Merkez Bölge, \\
Selimpaşa Liman Bölgesi, \\
Kentsel Yaşam Kalitesi ve Turizm \\
Potansiyeli, \\
Doku Bütünleşme, \\
Selimpaşa Tarihi Yapılar
\end{tabular}

\section{ÖZET}

İstanbul'a bağlı Silivri İlçesinin bir mahallesi olan Selimpaşa, son dönemlerde iç turizm potansiyeli açısından yükselen birçok kültürel, tarihi değere sahip olan bir sahil beldesidir. Selimpaşa'nın deniz kıyısında olması nedeniyle merkez yerleşimi dışında, sahil boyunca genelde 2 kattan oluşan yazlık konutların bulunduğu siteler yer almaktadır. Deniz kıyısı olmasının avantajının yanında tarihi bir değere de sahip olan Selimpaşa'da, özellikle yaz sezonu boyunca iç ve diş turizmden elde edilebilecek büyük bir ekonomik potansiyel bulunmasına rağmen, kültürel ve sanatsal aktivitelerin yer aldığı bir kentsel canlılık olmadığı gözlemlenmiş̦tir. Son yıllarda betonarme binalardan fazlasıyla nasibini almış olan Selimpaşa'da, restorasyon çalışmaları yapıldıktan sonra yeni işlev verilmesi halinde beldede yaşayan halka ve turizme kazandırılabilecek mimari ve tarihi değere sahip harap halde bulunan birçok bina ise kaderine terkedilmiș durumdadır. Ayrıca liman bölgesi ve ticari faaliyetlerin yer aldığı merkez kısmı da kot farkı nedeniyle birbirinden oldukça kopuktur. Bu bağlamda bölgede yapılan alan araştırması, analizler, yüz yüze anket çalışması ile mevcut problemler tanımlanmış ve özellikle merkez ve liman olarak seçilen iki mekanın doku bütünleşme önerisiyle birlikte, bölgedeki yaşam kalitesi ve turizm potansiyeline getirebileceği katkılar için çözüm önerileri geliștirilmiștir. Bu nedenlerle, konumu, kültürel kimliği, tarihi değeri, girisinde yer alan üniversite yerleşkesi, merkezde yer alan başka bir üniversitenin bölümleri, verimli topraklarında yetiştirilebilecek çeşitli tıbbi ve aromatik bitkiler ile iç ve dış turizm potansiyeli bulunan Selimpaşa sahip olduğu nitelikleri ile bu çalışmada araştırma konusu olarak seçilmiştir.

\section{Suggestions for Research and Use of Existing Potentials That Could Affect the Quality of Urban Life and Tourism Revival in the Coastal Town of Selimpaşa}

\section{ARTICLE INFO}

Article history:

Received: 25 April 2021

Accepted:14 June 2021

Key words:

Selimpaşa Centre Area

Selimpaşa Port Area,

Urban Life Quality and Tourism Potential,

Texture İntegration

Selimpaşa Historical Buildings

\begin{abstract}
Selimpaşa, a neighborhood of the Silivri District of Istanbul, is a coastal town that has many cultural and historical values, and that has recently risen in terms of its domestic tourism potential. Since Selimpaşa is on the seafront, where there are sites with generally two-storey summer houses along the coast apart from the central settlement. Although there is a great economic potential that can be acquired from domestic and foreign tourism particularly during the summer season, it has been observed that there is no urban liveliness of cultural and artistic activities in Selimpaşa, which has a historical value besides the advantage of being seafront. In Selimpaşa, which has exceedingly obtained its share from reinforced concrete buildings in recent years, many desolate buildings having architectural and historical value, which could be brought to the people living in the town and tourism in case of giving the buildings new functions with the restoration works, are left to their fate. Besides, the port area and the center, where the commercial activities are carried out, are also quite disconnected from each other due to the difference in elevation. In this context, the existing problems are identified through field research, analyses, and face-to-face surveys conducted in the region and particularly with the proposal of texture integration of two locations selected as center and port, solution proposals are developed for the possible contributions to the quality of life and tourism potential in the region. For these reasons, with its location, its cultural identity, its historical value, the university campus at its entrance, the departments of another university located at the center, the ability for various medical and aromatic plants to be grown in its fertile soils, and its domestic and foreign tourism potential, Selimpaşa is chosen as the research subject in this study.
\end{abstract}




\section{Giriş}

İstanbul'a bağlı Silivri İlçesinin bir mahallesi olan Selimpaşa, daha önceki yıllarda İdari bakımdan ayrı bir Belediye iken 2009 yerel seçimlerinden beri Silivri İlçesine bağlı mahalle statüsündedir. Konum olarak Marmara denizi kıyısında yer alması nedeniyle, yazın başlangıcında Mayıs ayından itibaren bölgeye II.konut sahiplerinin gelmesi ile 3-4 aylık süre içinde mevcut nüfusunda belirli sayıda artış görülmektedir. $\mathrm{Bu}$ nedenle yaz ve kış nüfusu oldukça değişkendir. Marmara Bölgesi ikliminin özellikleriyle genelde Eylül sonlarında yaz sezonu bitmekte özellikle okulların açılışı ile kışlık mekanlara dönüşler başlamaktadır. Yazlık olarak kullanılan konutların çoğunda 10 seneden fazla bir süredir doğal gaz bağlanmış olmasına rağmen kışın bu konutlarda kalma oranı oldukça azdır. Ancak 2020-2021 yılı kış aylarında koronavirüs (Covid-19) salgını nedeniyle müstakil ve siteler içinde yer alan konutlarda kalanların bir kısmının kışlık evlerine dönmediği tespit edilmiştir. Selimpaşa doğal bir güzelliğe sahip olmasının yanında tarihi kimliğini yansıtan mimari değere sahip bir çok binaya da ev sahipliği yapsa da bu binaların çoğu halen harap durumdadır. Restorasyonu yapılan az sayıda sivil mimari bina, kamu binası ve bir cami örneği dışındaki binalar yapısal olarak gün geçtikçe daha da onarılamaz hale gelmektedir. Bölgede çok az sayıda konaklama tesisi bulunmakta olup, yaz aylarındaki etkinlikler sadece Topatan Kavunu ve Bamya festivali ile sınırlı kalmakta bunun dışında turizmi canlandıracak kültürel ve sanatsal aktiviteler olmadığı görülmektedir. Bulgaristan ve Yunanistan'ın Trakya bölgesine sınır olması nedeniyle bu ülkelerdeki sahil beldelerine ülkemizden sıkça günlük ve kısa süreli turlar yapılmasına rağmen, tarihi bir geçmişi olan Selimpaşa'ya nerdeyse hiç yabancı turist gelmemektedir. Selimpaşa Mahallesi dokusal olarak incelendiğinde, merkez bölgesiyle liman bölgesi arasındaki topoğrafyadan kaynaklanan kot farkının, iki mekan arasında kopukluğa neden olması da liman bölgesinin mekânsal olarak kullanımını azaltmaktadır. Bölgenin, fiziksel arazi yapısına bağlı olarak geliştirilebilecek doğru bir planlama ve üst kotta yer alan harap binaların sağlamlaştırma (konsolidasyon) ve restorasyonları sonrası önerilecek yeni işlev değişikliği, mevcut üniversitelerle bağlantılı olarak sosyal ve kültürel aktivitelerin arttırılması, yaz aylarında düzenlenebilecek çeşitli tanıtıcı festivaller gibi bir çok faktörle, Selimpaşa'nın farklı bir kimliğe geçme potansiyeli çok yüksektir. Konumu, kültürel ve tarihi kimliği ile iç ve diş turizm potansiyeli gibi sahip olduğu bir çok özellikler, Selimpaşa'nın araştırma konusu olarak seçilmesinde önemli bir rol oynamıştır.

\section{Materyal ve Yöntem}

Bu çalışmanın amacı, olumlu birçok bileşene sahip bir mahallenin, bileşenlerinin bir bütün halinde kullanılamaması nedenlerinin araştırılarak fiziksel, sosyal, sosyo-ekonomik eksikliklerinin giderilebilmesi bağlamında çözüm önerileri geliştirilmesidir. Selimpaşa'nın sahil beldesi olması, karayoluyla kolay ulaşılabilirliği, kültürel ve tarihi değerler açısından zengin bir yer olması, girişinde yer alan Kadir Has Üniversitesi ve merkezde yer alan Fenerbahçe Üniversitesi Kampüs binalarıyla eğitim faaliyetlerini de barındırması olumlu bileşenlerden bazılarıdır.

Selimpaşa merkez ve liman bölgelerinin ve tarihi binaların olduğu alanlar yerinde incelenerek mevcut analiz çalışmaları yapılmıştır. Çeşitli kaynaklardan literatür taramaları ve bölgede yaşayan yerel halkla yüz yüze yapılan anketlerle çalışmalar desteklenmiştir. Fiziksel, sosyal, kültürel, sosyo-ekonomik veriler, kentsel yaşam kalitesi ve turizm potansiyelini arttıracak biçimde ele alınarak bu bağlamda öneriler geliştirilmiştir.

\subsection{Selimpaşa'nın Konumu ve Coğrafi Özellikleri}

Eski adı Epivatos olarak bilinen Selimpaşa, Marmara Denizi kıyısında İstanbul'un Avrupa yakasında bulunan Silivri ilçesinde bulunmaktadır (Şekil 1). Silivri'nin 12 kilometre güneydoğusunda, Bizanslılar tarafindan Epivati (Fundalık) adıyla kurulmuştur (Han, 2000). İstanbul il merkezine uzaklığı yaklaşık 55 kilometredir.
Selimpaşa'nın kuzeybatısında Silivri, güneyinde Marmara denizi, kuzeyinde Ortaköy ve doğusunda Kamiloba köyleri yer almaktadır. D-100 karayoluyla Edirne'yi İstanbul'a bağlayan yol, Selimpaşa'nın içinden geçmekte ve Eski Londra Asfaltı olarak da bilinmektedir. Bizans imparatorluğu döneminde ise Via Egnetia olarak bilinen Selimpaşa yoluyla İstanbul'a ulaşım sağlanmıştır. Bu yerleşim yeri, bölgeye eskiden beri deniz limanlarının ve kara ulaşımının bilinen bir durağı haline gelerek stratejik önem kazandırmıştır (Taşkın, 2002).

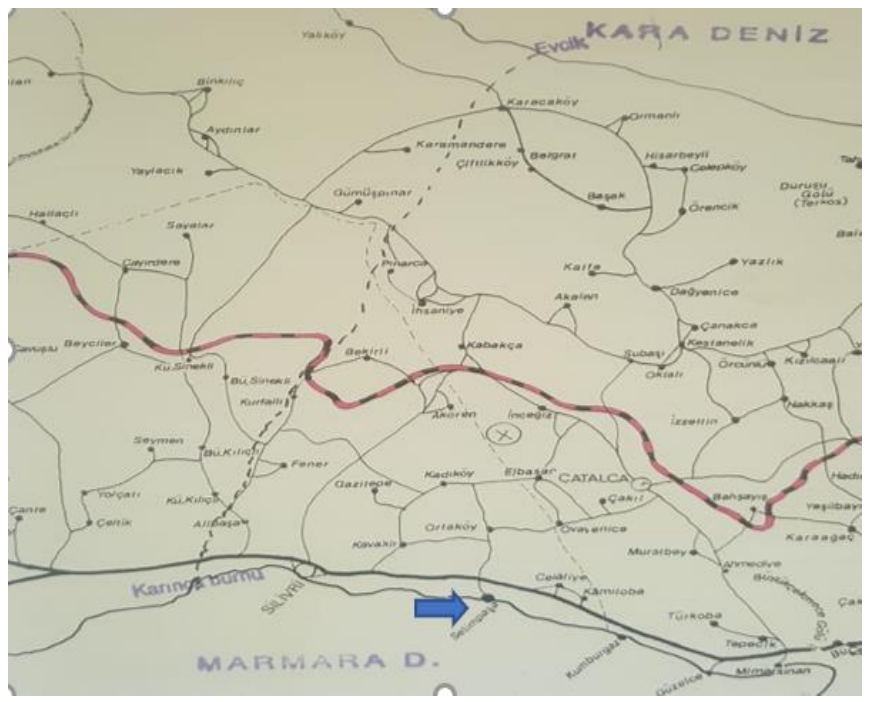

Şekil 1: İstanbul İli İçinde Selimpaşa (Kozanoğlu, 1994)

\subsection{Selimpaşa'nın Tarihçesi}

Selimpaşa'da M.Ö. VII. Yüzyılda ilk yerleşimlerin başladığı tahmin edilmektedir (Taşkın, 2002). Türklerin hakimiyeti altına 1360' yıllarda geçmiştir. Bölgede yaşayan nüfusun büyük bir çoğunluğu cumhuriyet yıllarında Rumlardan oluşmaktaydı. 1926 yılında yapılan mübadele ve göçten sonra bölgede tamamen Türk nüfus yaşamaya başlamıştır. Selimpaşa ile ilgili 19.yüzyılda Dr. Sarandi Arhiyeni tarafından yapılan önemli eserler günümüze kadar ulaşabilmiştir (Han, 2000).

\subsection{Selimpaşa'nın Tarihi Dokusu ve Yapıları}

Selimpaşa'da yapımı 19. Yüzyıla dayanan yaklaşık 46 adet sivil mimarlık örneği, 5 adette anıtsal yapısı bulunmaktadır. Tarihi dokuyu oluşturan binaların ahşap ve yığma yapılar olduğu görülmektedir. Yığma yapıların özellikle giriş katları taş ve tuğla olmak üzere iki çeşittir. Bu yapılarda pencere ve kapı çevresi küfeki taşı ve tuğla kullanılarak yapılmıştır. Sıva yapılmayan cephelerde ise, dönemin yapım tekniği ile küfeki taşı kaplama yapıldığı gözlemlenmiştir. Sokak dokusunun oluşturan taş yollar gerekli onarımdan yoksun olarak zaman içerisinde yok olmuștur. 1980'li yıllarda İstanbul'a yakınlığı nedeniyle İstanbul halkı tarafindan Selimpaşa yazlık mekan olarak kullanılmaya başlanmış ve burada sahil boyunca II.konut olarakyeni binalar inşa edilmiştir. $\mathrm{Bu}$ binalarla birlikte, özellikle bamya ekilen tarım alanları yok olmaya başlamıș ve yerini betonarme binalara terk etmiștir. Plansız büyümenin yanında kültürel ve tarihi değerlerin yok olmaya başlamasıyla 10.12.1991 ve 21.07.1992 tarihlerinde iki yeni karar izlemiştir (Han, 2000).

\subsection{Dini Yapılar}

19.yüzyıla kadar Selimpaşa'da sadece dört adet kilisenin olduğu bilinmektedir (Şekil 2). Bunlar; Osia Paraskevi, Aya Doodorosla, Meryem Ana ve Aya Yorgi kiliseleridir. 1808 yılında çıkan yangında kilise ve konutların çoğu yok olmuştur. Bu yangından Aya Yorgi ve Osia Paraskevi Kilisesi hasarla kurtarılmıştır. Ancak kilisenin küçük olmasından dolayı yıktırılmış ve yerine 1884 yılında moloz taş ve tuğladan Büyük Kilise inşa edilmiştir. 1980'li yı1llarda su basman seviyesine kadar yıkılarak yerine çocuk parkı yapılmıştır. 
Günümüzde ise, 55 pafta ve 5589 nolu parsel üzerinde kalmaktadır. Rum halkının mübadeleden önce son olarak 1926 yılında bu kilisede ibadetini yaptığı bilinmektedir. 1808 yılında çıkan yangından ufak bir hasarla kurtarılan 55 pafta 5851 nolu parsel üzerinde bulunan Küçük kilise, 1950 yılında Türklerin bölgeye göç etmesiyle birlikte yeni bir cami yapılana kadar kiliseye minare eklenerek cami olarak kullanılmıştır (Han, 2000).

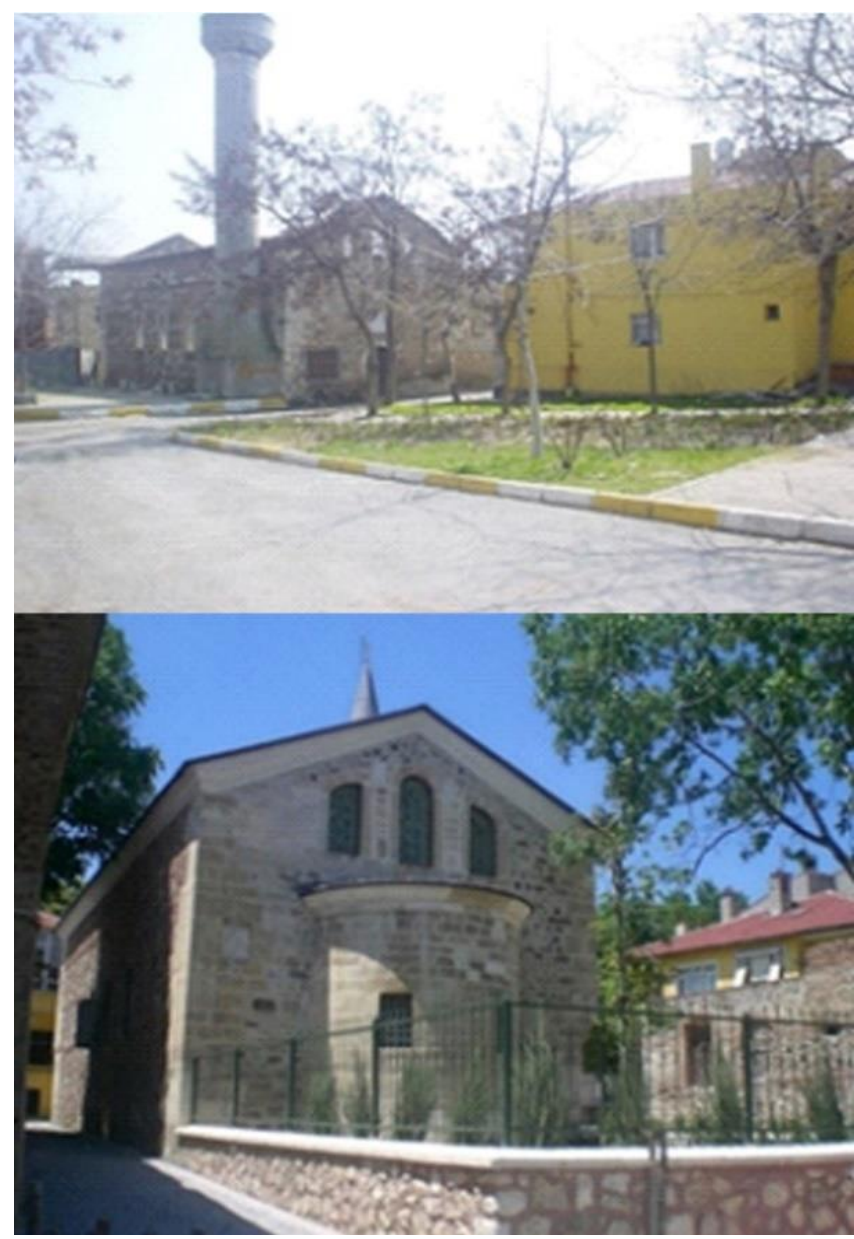

Şekil 2:Selimpaşa Tarihi Eski Caminin Restorasyon Öncesi ve Sonras1 (Foto: Zeynep Kerem Öztürk, 2005)

\subsection{Kamu Yapıları}

1796 yılında açılan okulla birlikte belde gelişerek merkezi bir hal almaya başlamış, Patrikhanenin himayesinde ise 1857 yılında bir okul daha açılmıştır. (Şekil 3)'deki bu okul göç sonrasında 1980'lere kadar ilkokul, daha sonra ilkokula ek bina olarak tasarlanmıştır. Günümüzde bu okul 35 pafta, 6986 nolu parselde yer almaktadır. Bina yapımında moloz tas kullanılmıs olup iki katlı ve kare plana sahip kübik bir mimarisi bulunmaktadır. Güney cephe tarafinda bulunan iki girişi vardır. Her iki katında da yer alan kemerli pencere söveleri kesme taştan yapılmıştır. Kat girişi dışarıdan olmakla birlikte simetrik olarak yapılmış iki merdiveniyle de zemin kotuna bağlanmıştır. Okul binasının köşe taşları kabartma motifli olup, cephelerde ise moloz taş kullanılmıştır. Kat ve saçak altı silmeleri kesme taştan yapılmıştır. Çatı kaplamasında ise marsilya kiremiti kullanılmıştır. Zaman içinde hasar gören yapıyı onaran kişilerin kalifiye olmaması nedeniyle bina yeniden kısa bir süreç içinde bozulmalara uğramıştır. Halen özgünlüğünü yitirmeyen bu binanın ufak müdahalelerle, gelecek kuşaklara miras olarak bırakılması planlanmaktadır.

Selimpaşa beldesinde yer alan diğer okullar ise 1857 yılında Arhigenya Vakfina aittir (Şekil4). Günümüzde ise bu yapıların sadece dört tanesi ayakta kalmayı başarabilmiştir (Han,2000).

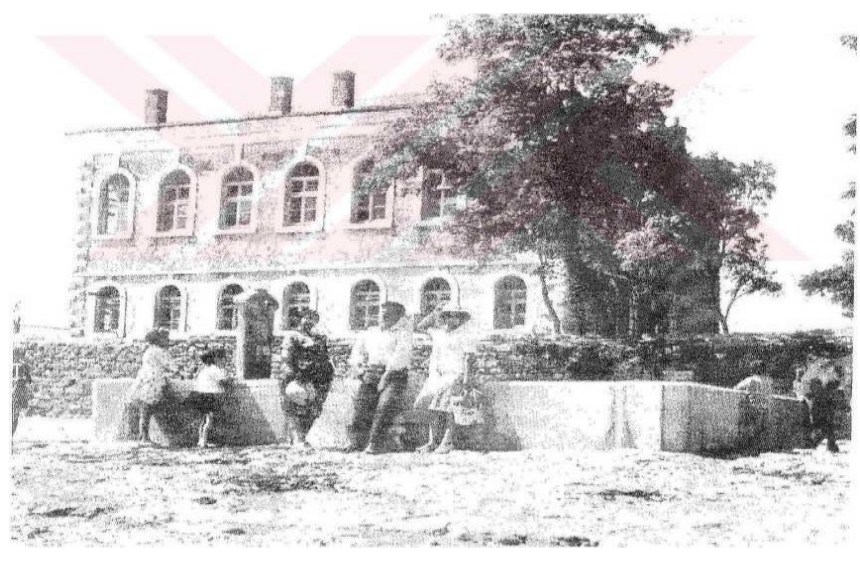

Şekil 3: 1950’li Yıllarda Okul ve Çevresi (George, 1999).

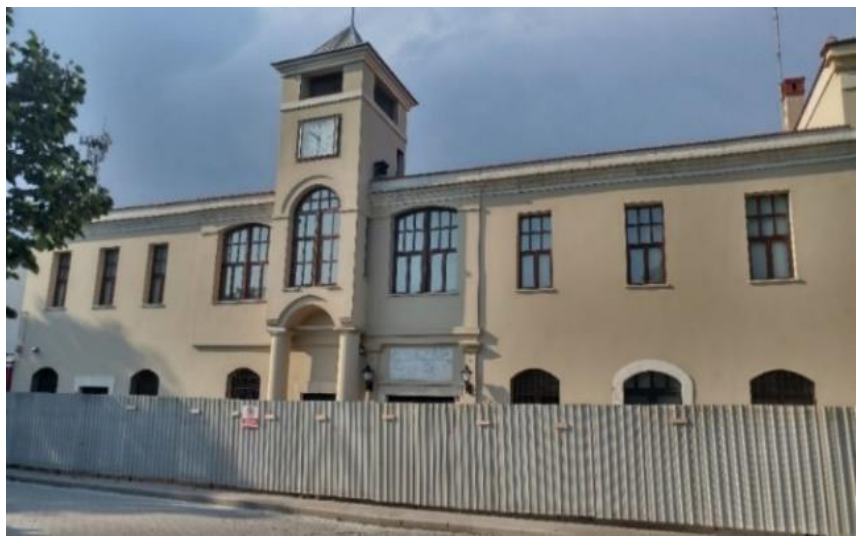

Şekil 4: Fenerbahçe Üniversitesi Selimpaşa Yerleşkesi Restorasyon Çalışmaları Devam Ederken (Foto: Mertcan Yılmaz, 2018)

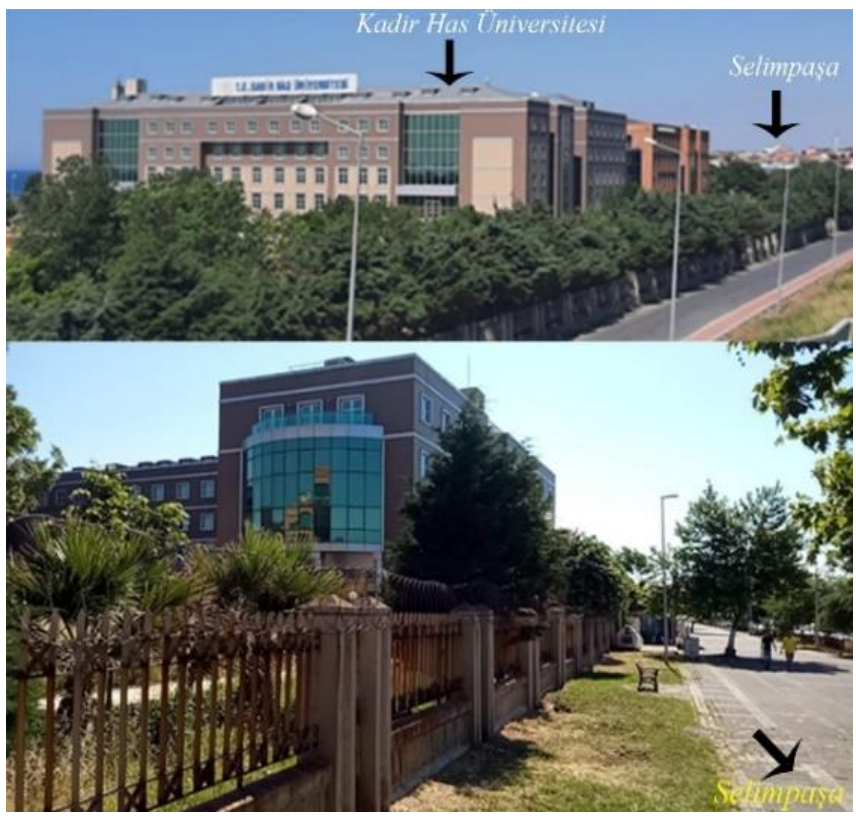

Şekil 5: Selimpaşa'da Kadir Has Üniversitesi (Foto:Zeynep Kerem Öztürk, 2021)

\subsection{Sivil Mimari Yapılar}

Bölgedeki konutların çoğunluğu ahşap olarak inşa edilmiştir. Ahşap binaların olumlu birçok özelliğinin yanında, yangına karşı korunaklı olmaması, 1808 yılındaki yangında birçok ahşap binanın yok olmasına neden olmuştur. Günümüze ulaşabilen ahşap binalar ise 19. Yüzyılda yapılmış olup büyük bir çoğunluğu iki katlıdır (Şekil $6)$. 


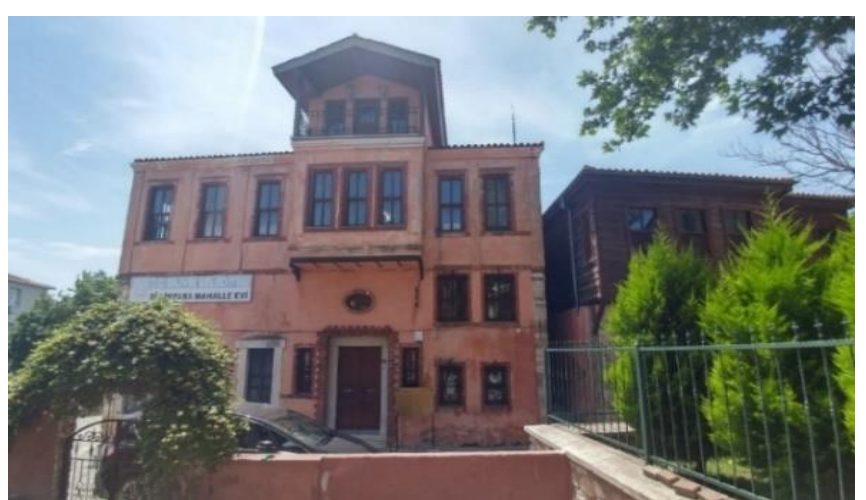

Şekil 6: Kadınlara Yönelik Kurslar Verilen Selimpaşa Mahalle Evi (Foto: Mertcan Y1lmaz, 2018)

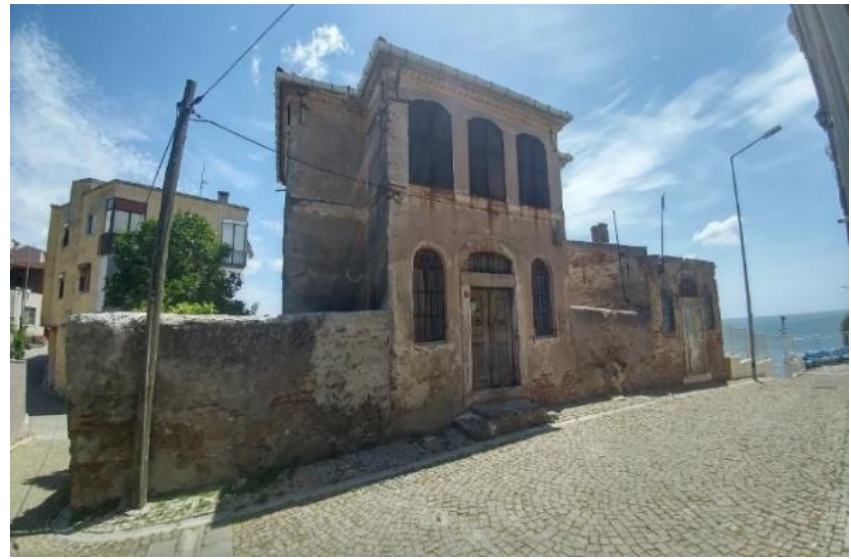

Şekil 7: Selimpaşa'da Harap Durumdaki Tarihi Bina (Foto: Mertcan Y1lmaz, 2018)

\subsection{Mevcut Doku Analizi}

Selimpaşa merkez, liman ve sit alanlarında yapılan analizler ve alan araştırmalarından edinilen sonuçlar değerlendirildiğinde bölgede genel olarak kat yükseklikleri arasında uyumsuzluklar, tarihi dokuyu yansıtmayan bir kimlik ortaya çıkmaktadır. Doğalgaz altyapısı olmasına rağmen, kışın halen bazı yerlerde kullanılan kömür sobası nedeniyle kömür dumanı havayı kirletmekte çevreye kömür kokusu yayılmaktadır. Topoğrafik verilere bakıldığında Selimpaşa'nın ticari aktivitelerinin yer aldığı merkez bölgesinden limana inen yol aksında liman bölümüne doğru artan eğimden dolayı doku kopukluğu oluştuğu görülmektedir. Ayrıca aynı bölgede bulunan atıl kalan (Şekil 7) yapılarında etkisiyle yaya sirkülasyonunda azalış bulunmaktadır.

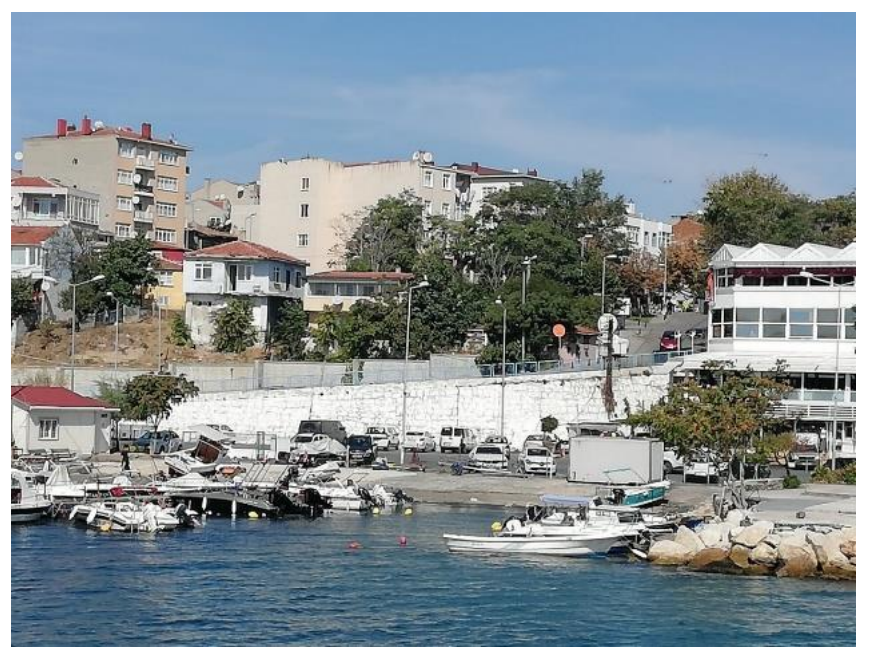

Şekil 8: Mevcut Araç Yolunun Denizden Görünüşü (Foto: Mertcan Y1lmaz, 2020)

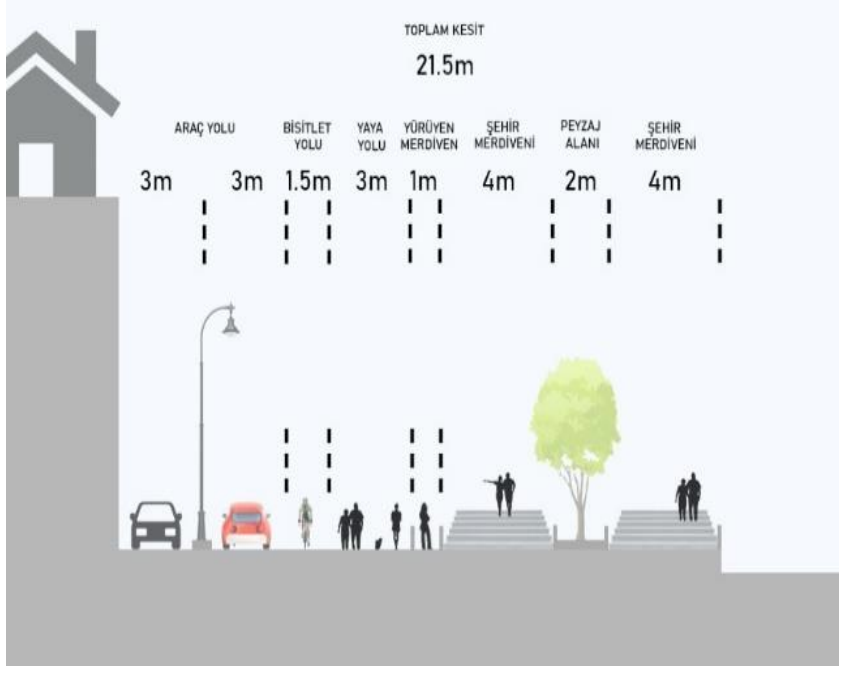

Şekil 9: Selimpaşa Mevcut Kot Farkına Çözüm Önerisi Kesit (Y1lmaz, 2020)

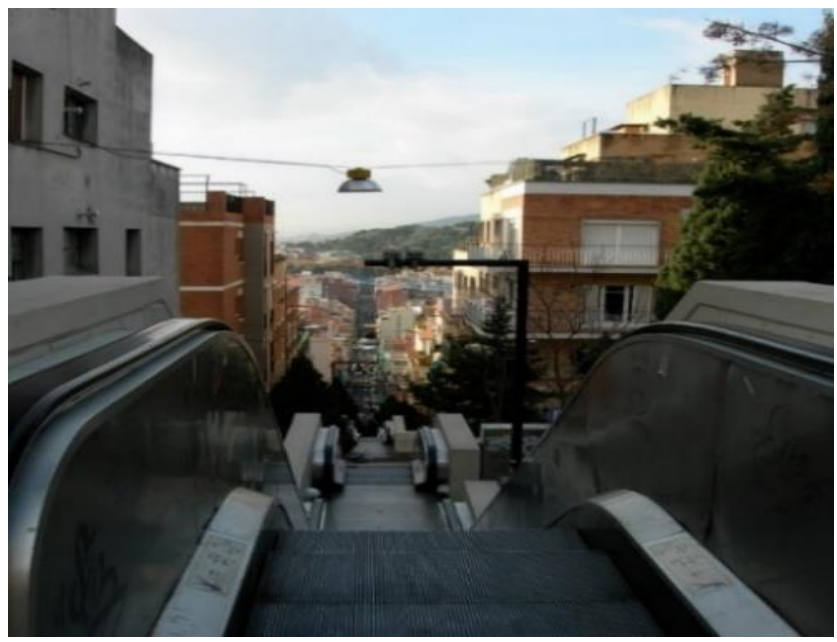

Şekil 10: Barselona'da Eğimli Bir Sokaktaki 'Yürüyen Merdiven' (Foto: Zeynep Kerem Öztürk, 2019)

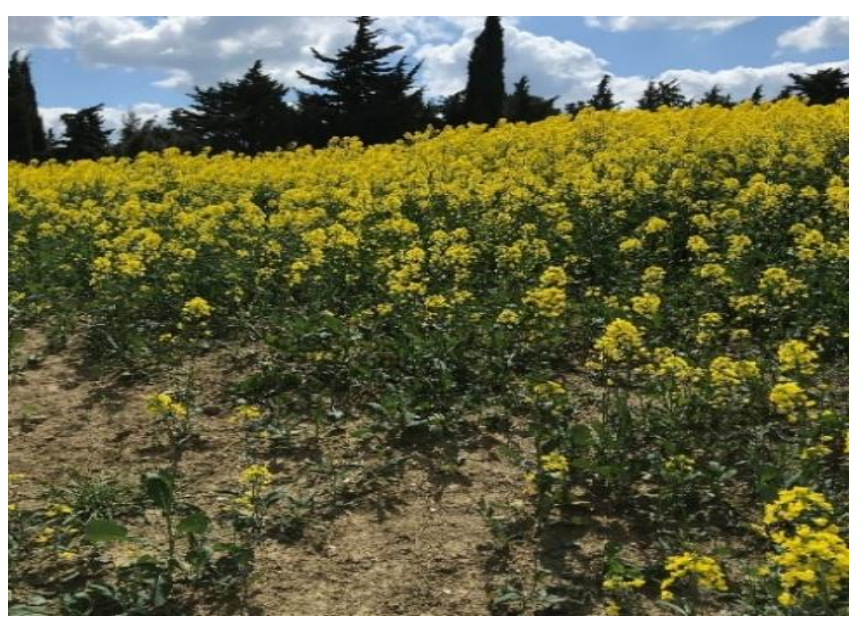

Şekil 11: Selimpaşa'da Hardal Otları (Foto: Zeynep Kerem Öztürk, 2018)

\section{Bulgular ve Tartışma}

Kentsel yaşam kalitesi ve turizm potansiyeli artışını sağlamak amacıyla, bölgede yaşayan yerel halkın görüşlerinin de etkili ve önemli bir parametre olduğu düşünüldüğünden saha çalışmasına karar verilmiştir. Bu veri toplama için anket yöntemi kullanılmıştır. 


\subsection{Yöntem}

Hipotezlerin sınanması için yüz yüze görüşme yoluyla anket yapılmıştır. Veri elde etme sürecinde bazı varsayımlar temel alınarak oluşturulan anket çalışmasında 5 kategori baz alınarak hazırlanmıştır. Yöntem olarak anket çalışması yapılmasının nedeni olası turizm potansiyelindeki etkilerin ve kentsel yaşam kalitesinin değişiminde yerel halkın yönelim ve düşüncelerinin de belirleyici bir unsur olarak düşünülmesidir. Burada yaşayan yerel halk ve ikinci konut sahipleri olarak iki profil baz alınmıştır. Anket soruları yerel halk için $33+7$ toplam 40 soru ikincil konut sahiplerine için ise $33+8$ toplam 41 sorudan oluşmaktadır. Selimpaşa'nın nüfusu 20.337 kişidir (TÜİK). Anket analizinde sağlıklı sonuç çıkabilmesi için asgari örneklem oranı olan \%1 baz alınarak anket 214 kişi üzerinde uygulanmıştır. Sonuçlar mevcut hipotezler üzerinde test edilmiş ve veriler tek tek grafik anlatımla değerlendirilmiştir (Yılmaz, 2020).

\subsection{Alan Araştırması Sonucu}

Alan araştırmasının sonucunda cevaplara ait frekanslar Tablo 1 'de görülmektedir. Kent Meydanına yapılacak işlev ile ilgili yerel halk ve ikinci konut sahipleri ortak olarak etkinlik alanı istemişlerdir. Tarihi konutlarla ilgili yanıtlarda ise yerel halk bu konutların müze ve kültürel etkinlik alanı yapılmasını isterken, ikinci konut sahibi kişiler ise etkinlik merkezi en yüksek seçenek olarak işaretlemişlerdir. Selimpaşa Limanına yerel halktan özellikle erkek nüfus balık almak ve çay içmek için sıkça inerken, ikinci konut sahipleri haftada veya ayda bir kez indiklerini belirtmiştir. Yerel halk liman bölgesini açık hava sinemasının canlandıracağını düşünürken, ikinci konut sahipleri sinemanın yanı sıra kafe ve restoranlarında olmasını istemektedir. Genel olarak değerlendirme yapıldığında Selimpaşa'daki kentsel canlanmayı sağlamak için ortak düşünce kentte bir etkinlik alanı oluşturulmasıdır. Merkezden limana inen yol aksının kesintisiz ve aydınlatmanın yeterli olması tüm kullanıcıların istediğidir (Yılmaz, 2020).

Tablo 1: Selimpaşa Liman ve Merkez Bölgesinin Sorularına Ait Frekanslar

\begin{tabular}{|c|c|c|c|c|}
\hline & & Yerel Halk & $\begin{array}{l}\text { İkinci } \\
\text { Konut }\end{array}$ & Toplam \\
\hline \multirow{5}{*}{$\begin{array}{l}\text { Selimpaşa meydanı ne tür bir işlevle } \\
\text { canlandırılabilir? }\end{array}$} & Su öğesi & 10 & 5 & 15 \\
\hline & Etkinlik Alanı & 48 & 62 & 110 \\
\hline & Oturma Alanları & 9 & 18 & 27 \\
\hline & Anıtsal Yap1 & 4 & 2 & 6 \\
\hline & Yeşil Alan & 28 & 28 & 56 \\
\hline \multirow{5}{*}{$\begin{array}{l}\text { Selimpaşa'da kullanılmayan tarihi } \\
\text { konut yapıları hangi işleve } \\
\text { dönüştürülürse bölgeye ve turizme } \\
\text { katkısı olur? }\end{array}$} & Hediyelik Eşya & 1 & 13 & 14 \\
\hline & Müze & 29 & 20 & 49 \\
\hline & Etkinlik Merkezi & 28 & 50 & 78 \\
\hline & Butik Otel & 24 & 26 & 50 \\
\hline & Kütüphane & 17 & 6 & 23 \\
\hline \multirow{5}{*}{$\begin{array}{l}\text { Selimpaşa limanına ne sıklıkla } \\
\text { iniyorsunuz? }\end{array}$} & Her gün & 31 & 5 & 36 \\
\hline & Haftada birkaç & 26 & 34 & 60 \\
\hline & Ayda birkaç & 25 & 35 & 60 \\
\hline & Y1lda birkaç & 15 & 26 & 41 \\
\hline & Hiç inmiyorum & 2 & 15 & 17 \\
\hline \multirow{5}{*}{$\begin{array}{l}\text { Liman bölgesinde hangi aktivite } \\
\text { olursa sahile inme sıklığınız artar? }\end{array}$} & Canlı müzik & 21 & 28 & 49 \\
\hline & Açık Sinema & 24 & 30 & 54 \\
\hline & Oturma alanı & 15 & 8 & 23 \\
\hline & Kafeler & 21 & 31 & 52 \\
\hline & Gece pazarı & 18 & 18 & 36 \\
\hline \multirow{5}{*}{$\begin{array}{l}\text { Selimpaşa Liman ulaşımı ne şekilde } \\
\text { düzenlenirse ulaşımı kolaylaşır? }\end{array}$} & Asansör & 10 & 22 & 32 \\
\hline & Yaya yolu & 32 & 48 & 80 \\
\hline & Merdiven & 23 & 21 & 44 \\
\hline & Yaya rampası & 3 & 5 & 8 \\
\hline & Işıklandırması & 31 & 19 & 50 \\
\hline
\end{tabular}

\section{Sonuc}

Selimpaşa'nın en önemli sorunlarından biri merkez ve liman bölgesinde bulunan harap durumda kullanılmayan atıl yapılardır. Bu yapılar 1808 yılındaki büyük yangın sonrası 19 . ve 20.yüzyıllarda yapılmış olan zemin katı yı̆̆ma taş ve tuğla, üst katları ahşap karkas yapılardır. Bu binalar Osmanlı döneminde Rumların yapmış olduğu dini mimari yapılar ve birçoğunun işlevi okul olan kamu mimarisi yapılar olup, 1991 yılında ilan edilen kentsel sit alanı içerisinde kalmaktadır. Çevrede birkaç restorasyon örneği hariç, özellikle konut mimarisi yapılarında uzun süredir herhangi bir onarım yapılmamıştır. Bir kısmında ise mülkiyet sorunu bulunmaktadır. Halbuki bu mimari yapılar özgün haliyle onarıldığında tarihi dokuyu yansitabilecek hem de konumu itibariyle turist çekebilecek potansiyele sahiptir.

Selimpaşa merkez ile liman arasında kalan dokunun mekansal planlamada bütünlüğünün korunması önem taşımaktadır. Bölge incelendiğinde Selimpaşa mahallesinin merkez bölgesinden limana doğru inen yolda hafif eğim görülürken, limana yaklaşıldığında (Şekil 8) 8-10 metreye ulaşan bir kot farkı oluşmaktadır. Liman inen mevcut araç yolu ve merdiven köhnemiş olup, merdiven rıhtları da yüksek olduğundan 
çocuklar ve yaşlılar bakımından tehlike arz etmektedir. Limanda bulunan birkaç tane balıkçı dükkanından alışveriş için insanlar genellikle arabalarıla limana inip geri dönmektedirler. Bu nedenle, Selimpaşa'nın merkeziyle limanı arasında topoğrafyasından oluşan kot farkı fazla olan yerlerde, limanın daha sık ve fazla kullanımı için yaya ulaşımının da önemi ortaya çıkmakta olup, yeni düşey sirkülasyon elemanlarına ihtiyaç vardır. Açık mekanda kullanıcıları yormayacak şekilde riht yüksekliği ile uygun basamak genişliğine sahip ve mimari estetik değer taşıyan merdivenler, standartlara uygun yaya rampası, asansör gibi elemanlar düşey sirkülasyonu sağlayarak insanların farklı kotlardaki mekanlara ulaşımını hızlandıracaktır. Ayrıca Barselona örneğinde olduğu gibi (Şekil 10) eğimli sokaklarda uygulanmış olan yürüyen merdivenler konulması da başka bir seçenektir. Düşey sirkülasyonda kullanılabilecek tüm öğelerin yerinde yapılacak fizibilite çalışmalarından sonra seçimine karar verilmesi gerekmektedir. $\mathrm{Bu}$ çalışmada geliştirilen öneri seçeneğinde, mevcut araç yolu rampası yeniden ele alınarak yol genişletilmiş, araç yoluna ek bir bisiklet yolu ve yaya yolu eklenmiştir. Mevcut araç rampasına paralel olacak biçimde engelli ve yaşlı bireyleri ihtiyacını karşılamak üzere bir adet yürüyen merdiven, yeni düzenlenmiş kent merdiveni ve iki metre genişliğinde yeşil bant bırakılmıştır. Tasarım ölçütlerinde engelliler için kriterler değerlendirilmelidir. Eski merdivenin olduğu yere ise panoramik asansör eklenmiştir.

Selimpaşa ulaşım açısından üst ölçekte düşünüldüğünde, ulaşımın tamamıyla karayoluyla sağlandığ 1 görülmektedir. Bu durum özellikle bir sahil kasabası için yeterli değildir. Liman bölgesinde sadece balıkçı barınağının tarihi dokuya uygun bir biçimde genişletilmesi ve çeşitli nitelikteki deniz taşıtlarının ulaşımına olanak verecek şekilde limanda düzenlemeye gidilmesi ile deniz ulaşımına da uygun hale gelecektir. Özellikle Yenikapı'dan başlamak üzere Bakırköy, Avcılar, Büyükçekmece gibi sahilde yer alan yerleşim alanlarından deniz ulaşımı ile Selimpaşa'ya bağlantı sağlanması durumunda, karayolu dışında bir ulaşım seçeneği oluşarak karayolunun yükü de özellikle yaz aylarında azalmış olacaktır. $\mathrm{Bu}$ seçeneğin iç turizm potansiyeline de katkı sağlayacağı düşünülmelidir.

Kentsel planlama çalışmalarında arazi kullanım modellerine bakıldığında, bazı faaliyetler belirli dügüum noktaları tarafından çekilmektedir. Örneğin üniversite dügüm noktası ise, iyi eğitimlilerden oluşan ikametler oluşarak kitapçıları çekmektedir. Selimpaşa'nın merkezinde (Şekil 4) ve girişinde (Şekil 5) yer alan üniversite kampüsleri ise birer düğüm noktası olarak ekonomik canlanmaya neden olabilecek ve yeni ticari aktivitelerin oluşmasında etken olacaktır. Öğrenciler için kiralık daireler, kitapçı, kırtasiye, ozalitçi, kitap-kafeler bu oluşuma örnek verilebilecek ticari faaliyetlerdir.

Silivri Belediyesinin tarımsal faaliyetleri arasında son yıllarda lavanta ekimi de önemli bir yer tutmaktadır. Tibbi ve aromatik bitkiler içinde ekonomik değeri ve kullanımı artan bitkilerden olan lavanta yetiştiriciliğinin, bulunduğu bölgeye ve ülke tarımına kattığ1 değer düşünüldüğünde, Selimpaşa'da kaybedilen tarım topraklarının yeniden kazanılması için bir seçenek olarak görülmesi mümkündür. Bunun yanında baharat olarak kullanılan hardal otu (Şekil 11), kinoa, kudret narı, enginar, karabuğday bitkileri de yetişmekte olup, özellikle yıllardır ekildiği halde imar faaliyetlerine yenik düşen bamya ve topatan kavunun ekimine devam edilmesi de tarımsal faaliyetlerde önem taşımaktadır.

Tarım arazilerinin kullanımı, tarihi yapılara restorasyon ve yeni işlev verilmesi, liman ve merkez bölgelerinde doku bütünleştirilmesi, küçük bir üniversite kentine dönüşüm, rekreasyon alanları ile liman ve deniz kıyısından daha aktif olarak yararlanmak öncelikli hedefler olarak belirlenmelidir.
$\mathrm{Bu}$ bağlamda, kentsel alanın tümüne yayılmış her sektörü kapsayacak bir Kentsel Canlanma oluşabilmesi Selimpaşa'nın bünyesinde bulunan mevcut potansiyellerinden doğru ve kararlı bir biçimde yararlanılmasına bağlıdır.

\section{Kaynaklar}

George, K., (1999). Epivati'den Anılar - Yarına Umutla Bakarken, Selanik.

Han, B. (2000). "Silivri-Selimpaşa Tarihsel Sit Alanı ve Arhigenya Kız Öğretmen Okulları Araştırma ve Değerlendirme Projesi”. Yüksek Lisans Tez, Yıldız Teknik Üniversitesi Fen Bilimleri Ens., İstanbul.

Kozanoğlu, C. (1994). Her Yönüyle Silivri, Silivri Belediyesi Kültür Evi Yayını.

Tarımsal Üretim ve Araştırma Merkezi, Silivri Belediyesi Kültür Evi Yayını (2019).

Taşkın, S. (2002). "Silivri-Selimpaşa Kentsel Sit Alanında Tarihsel Çevre Korumaya Yönelik Bir Araştırma ve Küçük Kilise Koruma Projesi", Yüksek Lisans Tezi, Yıldız Teknik Üniversitesi Fen Bilimleri Ens., İstanbul.

TÜİK. Türkiye İstatistik Kurumu. http://www.tuik.gov.tr

Yılmaz, M. (2020). "Selimpaşa Merkez ve Liman Bölgesinde, Doku Bütünleşme Önerisinin, Kentsel Yaşam Kalitesi ve Turizm Potansiyeline Etkileri”, Yüksek Lisans Tezi, Sabahattin Zaim Üniversitesi Lisansüstü Eğitim Ens., İstanbul 